\title{
Drawing Conclusions: Confusion Between Data and Theory in the Traumatic Memory Debate
}

\author{
Joyanna Silberg
}

KEYWORDS. Traumatic amnesia, traumatic memory, memory debate, childhood sexual abuse, sexual abuse prosecution, sexual abuse non-disclosure

The topic of traumatic memory has been a contentious and emotionally laden scientific controversy. The passion on both sides of the controversy has often led debaters to mischaracterize positions on the others side, leading to an imprecision in language and unscientific thinking that has clouded a debate that should at this point be closer to some acknowledged scientific consensus. Specifically, the consensus I have in mind, as stated by prominent cognitive psychologists, is the following: "Even the most conservative assessment of the evidence indicates that traumatic memories can fluctuate in their persistence, with periods of time in which the memories are relatively less accessible" (Edwards, Fivush, Anda, Felitti, \& Nordenberg, 2001, p. 174); or: "The data converge on the conclusion that many survivors of childhood sexual abuse claim periods of amnesia for the traumatic experience" (Sivers, Schooler, \& Freyd,

Dr. Joyanna Silberg coordinates trauma disorder services for children and adolescents for Sheppard Pratt Health System and serves as the executive vice-president of the Leadership Council for Mental Health, Justice and the Media. She is past president of the International Society for the Study of Dissociation, and editor of, The Dissociative Child (1998), The Sidran Press. She lectures nationally and internationally on the treatment of dissociative symptoms in traumatized children

Address correspondence to: Joyanna L. Silberg, PhD, 6501 North Charles Street, P.O. Box 6815, Baltimore, MD 21285-6815 (E-mail: jlsilberg@aol.com).

Journal of Child Sexual Abuse, Vol. 12(2) 2003

http://www.haworthpress.com/store/product.asp?sku=J070

(C) 2003 by The Haworth Press, Inc. All rights reserved.

10.1300/J070v12n02_08 
2002, p. 250). We do not yet have a complete scientific understanding of the memory processes involved, but a variety of explanations have been offered, including active forgetting involving functional inhibition (Anderson, 2001), fluctuating levels of meta-awareness (Schooler, 2001), psychological defensive processes such as repression or dissociation (Sivers et al., 2001), physiologically based theories involving stress-induced impairment of the hippocampus (Bremner, 2001), and betrayal trauma theory (Sivers et al., 2001). Some research data exist to support some aspects of all of these, but none have emerged as the most clearly explanatory of all of the data.

Goodman et al.'s (2003) study has offered important new findings, but is plagued by imprecision in language and extrapolation beyond the data that may very well lead to the results being misunderstood, misapplied, and misquoted, thus shedding further confusion rather than light on this important topic. This would be an unfortunate result of an article that is a major contribution to the literature as it addresses memory for sexual abuse events in a population that has rarely been researched-a prosecution sample. Jennifer Freyd's incisive comment (this issue) explains why a prosecution sample cannot necessarily be generalized to a non-prosecution population, and the reader is referred to her comment for a complete analysis of that issue.

In brief, in a follow-up of 168 children whose cases of sexual abuse were prosecuted in the court, Goodman et al. (2003) found that $15.5 \%$ did not report the targeted case when asked about it in a phone interview. In addition 1.1\%, or two cases, reported that they had no memory for the events even though they had been told that they had been victims of sexual abuse. The authors examined factors associated with non-disclosure and found that maternal supportiveness, later age of abuse, and severity of abuse were associated with disclosure. Contrary to prediction, relation to perpetrator and self blame (based on a psychoanalytic theory of repression) did not predict lack of disclosure.

One of the chief problems in this ongoing debate is that debaters have often confused two very distinct and separate scientific processes-reporting on observational data and generating hypotheses to explain the observations. Specifically, the observation that some people subjectively report no access to memory of sexual abuse is simply an observation, documented repeatedly in a variety of clinical reports, case reports, and research studies (for a summary of these studies, see Brown, Scheflin, \& Whitfield, 1999). In itself, this phenomenon is open to a variety of scientific interpretations. The fact that researchers have not yet settled on what theory best explains the phenomenon does not invalidate the observations that have led to these various speculative theories. Similarly, cosmologists offer many different theories regarding the origins of the universe, but few people would say the lack of agreement about a theoretical explanation implies the universe does not exist at all! Yet this same logic is 
used in the memory debate to discount observational data about this phenomenon. A process of polarization has emerged that leads to misrepresentation of critics' arguments and extrapolation beyond the data to bolster a one-sided position. Science advances through a process of theoretical synthesis of disparate results, rather than rejection or omission of what cannot be accounted for.

The opening of the Goodman et al. (2003) article sets out the problem in a way that reflects these very problems. Rather than review the abundant research which clearly demonstrates the existence of cases in which documented abuse was forgotten, the authors review only two retrospective studies (Briere \& Conte, 1993 and Elliot \& Briere, 1995) and two prospective studies (Widom \& Morris, 1997 and Williams, 1994) and present this as if this covers the entire field. Yet documentation exists for the robust finding across 100 years of research that some salient traumatic events are forgotten (Sivers et al., 2002). Then Goodman et al. confuse the nature of the debate, describing it as "whether for highly traumatic events, special memory mechanisms supercede normal memory processes" (p. 113). The authors put forward a straw man version of theories of traumatic amnesia, and imply that disproving this straw man theory could invalidate the existence of documented cases of traumatic amnesia. They further presume that their research design could shed light on the question of whether "special memory mechanisms supercede normal memory processes" (p. 113), without defining or operationalizing any of these terms.

Their research design could clearly shed light on whether there is any forgetting of documented abuse; indeed, they found that there was. Their research design could also shed light on whether some known theories about traumatic memory may account for the pattern of forgetting reported. In fact, they found some support for the theory of dissociation as well as the theory that maternal support predicted memory. Yet their research design as described could not successfully determine whether "special memory mechanisms supercede normal ones." Of the many theories that have been put forth to account for traumatic forgetting (as listed above), they have chosen to look at a very small number of variables associated with only a small subset of these theories. They do not define why they believe any of the examined theories are outside the realm of "normal cognitive operations," do not describe which operations they consider "normal," nor describe how they will measure the degree with which these supposedly "normal processes" supercede the others.

The operationalizing of the few "special memory mechanisms" under consideration in the Goodman et al. (2003) study-dissociation, repression, betrayal trauma-is highly questionable and could not be viewed as exhaustively eliminating all possible theories of traumatic memory. In a prosecution sample, where the secrecy, betrayal, and silent suffering of the victims would be significantly less, it would be hard to replicate the conditions theoretically and 
often empirically associated with traumatic amnesia. Thus, Goodman et al. using a very restricted sample, confound the observational data (does forgetting of highly traumatic events occur?) with theory generation (why does this occur?), and then lump together all possible theories to account for forgetting of highly traumatic events and subsume them under "special mechanisms."

Furthermore, the use of the term "special mechanisms" is a confusing term that obfuscates rather than clarifies. Whatever memory mechanisms exist in relation to traumatic events are part of the evolutionary development of the human brain and are not outside of science or outside of known processes. Researchers know well that emotional arousal during an event will no doubt have some impact on how the information is encoded, how it is retrieved, and what physiological correlates are associated with it. The process of scientific description involves both general principles and specific elaborations on those principles. To call that process of elaboration outside of "normal memory processes" obscures the nature of the scientific phenomenon being studied. This placing of theories of traumatic memory outside normal cognitive processes with the use of this term could be viewed as a subtle ad hominem argument that minimizes the study of traumatic memory by accusing scientists who study it as being removed from the mainstream of scientific discourse.

Goodman et al. (2003) then continue with similar imprecise language when they draw conclusions about their study: "These finding do not support the existence of special memory mechanisms unique to traumatic events, but instead imply that normal cognitive operations underlie long term memory for CSA" (p. 117). After finding that some of the variables did not predict forgetting in their small and highly specialized sample, they made a sweeping theoretical leap that implies they had ruled out all possible theories of traumatic forgetting, which they term "special memory mechanisms unique to traumatic events." Then, having ruled out these theories, they felt justified in ignoring the data themselves, the two cases of apparent traumatic forgetting that existed in their own study! Had they seriously intended to study the memory mechanisms involved in forgetting traumatic events, they might have focused specifically on the two patients who claimed to have no memory at all for the abuse. Those patients appear to demonstrate the phenomenon that has interested cognitive scientists-the experience of an extremely traumatic event and having no subjective feeling of recall. Science should logically move from data (these interesting subjects) to theory generation, not from theory rejection to rejection of the data themselves.

While their study found that for a majority of subjects in a prosecution sample, severity of abuse positively correlated to memory, this finding in no way addresses the unique characteristics that predispose some individuals to forget 
very salient events, including two of the subjects in their own study. In fact one of the variables that presumably is one of the "special mechanisms" they have discarded is "dissociation," and yet they found dissociation was positively associated with non-disclosure, a finding that they did not explain and did not seem to be consistent with their stated conclusions.

A true cognitive study of the phenomenon of forgetting traumatic events would need a larger sample to carefully document those cases that were true examples of subjectively experienced forgetting and would need to separate out variables associated with various competing theories. It is most likely that it is a unique combination of very specific circumstances that lead traumatic events to be forgotten in a process that follows known principles of memory. Such a study would help delineate the circumstances leading to traumatic forgetting and theorize about their association with known cognitive principles, as part of the building process of scientific knowledge.

It is possible that the contentiousness in the political and legal arena has been one of the reasons for the imprecision in language that has crept into this scientific debate. Researchers drawn into testifying for one side or the other on highly publicized legal cases may be prone to generalize and simplify, rather than present the kind of complexity that is characteristic of research results. The civil law suit in Boston being brought by Paul Busa and Gregory Ford against Rev. Paul Shanley will apparently revolve around the possibility of accurate recovered memories (Davis, 2003). According to the Boston Globe, Elizabeth Loftus will be presenting a key argument for the defense that such a phenomenon is not possible. Goodman et al.'s (2003) data itself, that two individuals had no memory at all for the documented case of abuse and $12 \%$ did not disclose the target incident, could be used to suggest that loss of memory for salient abuse events does in fact occur. (Of course, the question of whether these memories could then be accurately recovered is a question not addressed in this research at all.) Yet, those who testify for the defense could quote the imprecise Goodman et al. conclusions, and state that these findings "imply that normal cognitive operations underlie long term memory for CSA" (p. 117), thus falsely implying that dissociation was ruled out (which it was not) and falsely implying that all subjects who had been through the highly salient event of having their abuse prosecuted, remembered the abuse, which they did not. Hopefully, scientists asked to report about this study in court will not be misled by the concluding paragraph, and the way the issues were framed, and simply report on the interesting data based findings contained in the results and discussion sections. 


\section{REFERENCES}

Anderson, M. C. (2001). Active forgetting: Evidence for functional inhibition as a source of memory failure. In J. Freyd \& A. DePrince (Eds.), Trauma and Cognitive Science: A Meeting of Minds, Science and Human Experience (pp. 185-210). Binghamton, NY: The Haworth Trauma and Maltreatment Press.

Bremner, J. D. (2001). A biological model for delayed recall of childhood abuse. In J. Freyd \& A. DePrince (Eds.), Trauma and Cognitive Science: A Meeting of Minds, Science and Human Experience (pp. 165-184). Binghamton, NY: The Haworth Trauma and Maltreatment Press

Briere, J., \& Conte, J. R. (1993). Self-reported amnesia for abuse in adults molested as children. Journal of Traumatic Stress, 6, 21-31.

Brown, D., Scheflin, A. W., \& Whitfield, C. L. (1999). Recovered memories: The current weight of the evidence in science and in the courts. The Journal of Psychiatry \& Law, 27, 5-156.

Davis, W. (2003, March 5). The church hires a psychologist who doubts repressed memories. The Boston Globe, p. A16.

Edwards, V. J., Fivush, R., Anda, R. F., Felitti, V. J., \& Nordenberg, D. F. (2001). Autobiographical disturbances in childhood abuse survivors. In J. Freyd \& A. DePrince (Eds.), Trauma and Cognitive Science: A Meeting of Minds, Science and Human Experience (pp. 247-263). Binghamton, NY: The Haworth Trauma and Maltreatment Press.

Elliot, D. M., \& Briere, J. (1995). Post-traumatic stress associated with delayed recall of sexual abuse: A general population study. Journal of Traumatic Stress, 8, 629-647.

Freyd, J. J. (2003). Memory for abuse: What can we learn from a prosecution sample? Journal of Child Sexual Abuse, 12(2), 97-103.

Goodman, G. S., Ghetti, S., Quas, J. A., Edelstein, R. S, Alexander, K. W., Redlich, A. D., Cordon, I. M., \& Jones, D. P. H. (2003). A prospective study of memory for child sexual abuse: New findings relevant to the repressed memory controversy. Psychological Science, 14(2), 113-118.

Schooler, J. W. (2001). Discovering memories of abuse in the light of meta-awareness. In J. Freyd \& A. DePrince (Eds.), Trauma and Cognitive Science: A Meeting of Minds, Science and Human Experience (pp. 105-136). Binghamton, NY: The Haworth Trauma and Maltreatment Press.

Sivers, H., Schooler, J., \& Freyd, J. J. (2002). Recovered memories. In V. S. Ramachandran (Ed.), Encyclopedia of the Human Brain. Volume 4 (pp 169-184). San Diego, CA: Academic Press.

Widom, C. S., \& Morris, S. (1997). Accuracy of adult recollections of childhood revictimization. Part 2: Childhood sexual abuse. Journal of Consulting and Clinical Psychology, 62, 1167-1176.

Williams, L. M. (1994). Recall of childhood trauma: A prospective study of women's memories of child sexual abuse. Journal of Consulting and Clinical Psychology, $62,1167-1176$. 